\title{
An Empirical Study on Selection of Supply Chain Partner by Multi-Criteria Decision Making Method VIKOR - A Case of Automotive Industry
}

\author{
K.G. Rajasekaran ${ }^{1}$, G.B.Bhaskar ${ }^{2}$, S.Murali ${ }^{3}$, M.Chandrasekaran ${ }^{4}$ \\ ${ }^{1}$ Research Scholar, Department of Mechanical Engineering, Sathyabama University, Chennai, India. \\ kgrajasekaran16@gmail.com \\ ${ }^{2}$ Associate Professor, Department of Production Engineering, \\ Anna University, MIT Campus, Chennai, 600044. India. \\ ${ }^{3}$ Associate Professor, Department of Mechanical Engineering, Vels University, Chennai, 600117. India. \\ ${ }^{4}$ Professor, Department of Mechanical Engineering, Vels University, Chennai, 600117. India.
}

Abstract:A supply chain is a network of entities directly or indirectly interlinked and interdependent in performing activities in moving a product or service from supplier to customer. In recent times, the role of purchasing in supply chain continues to receive growing attention. The supplier selection process is a multi-objectives problem, encompassing many tangible and intangible factors include quantitative and qualitative data in a hierarchical manner. In this study, a methodology is proposed to establish the supplier selection criteria and ranking of selected supply chain partners based on these criteria. This is achieved through the employment of powerful multi criteria decision making (MCDM) method VIKOR that will help decision makers in the procurement to attain better quality of products. A case study is carried out to exhibit the effectiveness of the developed method in a firm involved in manufacturing the automotive components.

Keywords: Supply chain management, supplier selection, Multi criteria decision making, VIKOR.

\section{INTRODUCTION}

Over the last two decades the business environment has been considerably changed by increasing trend in intricacy, uncertainty and unpredictability. Organisations are now understanding that no longer they able to maintain a competitive advantage in the markets [1].

The present competitive environment, making pressures on firms to adopt the effective supply chain management [2], build up long-term strategic relationships with a capable and pioneering suppliers and work in partnership with them in non-core process outsourcing in order to improve overall performance and generate sustainable competitive advantage. It indicates that one of the competencies important to the supply chain success is an effective partner or supplier selection decision.

A supply chain is a system of organizations, people, technologies, activities, information and resources involved in moving a product or service from supplier to customer. Supply chain management, which encompasses the planning and management of all the activities involved in sourcing, procurement, conversion \& logistics management and also include the collaboration with the suppliers, intermediaries, third-party service providers and customers. Supply chain activities involve transformation of natural resources, raw materials and parts into a finished product that is delivered to the customer. Hence, maintaining a perfect supply chain across all its operations, thus becomes essential for any business.

Procurement or purchasing in the supply chain may be termed as the effective acquisition of goods or services and involves buying the raw materials and components for the organization. It is important that the goods or services procured at the lowest possible price to meet the needs of the purchaser in terms of quality, quantity, time and location. According to De Boer et al. [3], a supplier selection task consists of four stages, namely, problem definition, formulation of criteria, evaluation of suppliers and final selection of the ultimate supplier. Based on this background, the main purpose of the present study is to identify the supply chain partner selection criteria and select the best supplier by ranking of suppliers through MCDM method.

\section{RESEARCH BACKGROUND}

The procurement task has gain importance in the supply chain management due to the factors such as globalization, increased value adding in supply and accelerated technological change. Many reasons affect a organisation's ability to select the right supplier and hence there is a need to understand and realize the importance of the supplier selection criteria. Cox [4], identified some of the criteria which affect the supplier selection, such as trust and commitment, adequate finance, quality, reliable delivery times and adequate logistic 
and technological capabilities. Other criteria such as materials delivery, price, financial position, communication, technology, consistency, credibility and product development are also studied in the previous studies. This shows that the firms are shifting their focus from solely concentrating on quantitative issues to qualitative criteria [5].Many researchers [6] pointed out that the factors such as multiple criteria, association of many alternatives and internal/ external constraints make the supply chain partner selection process more complicated and it takes a lot of work, effort and endurance to build up this collaboration. The suppliers who can deliver the materials or services at right quantity, at the right time, at the right price and at the right quality are termed as potential supplier. It is clear that the effective supplier selection must deal with a mass of quantitative and qualitative factors that may be in conflict with one another [6].

\section{A. Supplier Selection Criteria}

Stanley and Gregory [7] proposed the model for supplier selection which consists of the criteria such as (i) Cost - includes purchase of material or part, transportation cost, taxes and operational costs, (ii) Technical capability - includes suppliers' technical competency, production planning ability, maintenance activities of suppliers and plant layout [5], (iii) Quality - rejection rate, quality assessment in production, inspection and experimentation and quality assurance in supply chain [8]. (iv) Organizational profile - includes attainment of sales and marketing goals, financial performance and strategy for technology age, (v) Service level - includes attributes such as delivery, lead time and easy of communication [8], (vi) Supplier's profile - comprises the performance and past history of the suppliers includes financial status, response of customers etc., (vii) Risk Factor - includes exogenous factors such as geographical location and political stability[4] help in taking decisions for the selection of supply chain partner.

Bhutta and Huq [9] found that, explicit criteria such as quality, service, delivery and price and implicit criteria such as reputation and location are the important factors that influence the supplier selection. According to Tracey and Tan [2], the firm performance and customer satisfaction are enhanced by selection of suppliers based on the criteria such as quality, delivery reliability and product performance. Petroni and Braglia [10] studied and evaluated the performance of suppliers based on management capabilities, production facilities, technology, price, quality and delivery compliance.

Lamming et al. [11] recommended that the management of suppliers for functional products must focus on cost and quality issues, whereas for unique innovative products, the emphasis is on speed and flexibility. Kotabe and Murray [12], revealed that supplier's competency, service quality control, transaction-cost drivers, supplier's brand image and supplier's country characteristics are more important criteria than others. Shahadat [13] found that price and timely delivery are primarily influenced criteria followed by the reliability of the supplier and the quality of products. Kannan and Tan [14] revealed that cost and price are having greater impact than the supplier commitment.Previous research studies found that the supplier evaluation and selection varies depends upon the factors such as products and services, but there was a similarity in the factor purchase decisions $[15,16]$. From the literature survey, it is found that most of the studies were considered quality, price, delivery and service as prime factors when evaluating supply chain partners.

\section{III.MULTI CRITERIA DECISION MAKING METHODS}

In business enterprises and everyday life, decisions involving multiple criteria are the most difficult to make and yet they are often the most crucial. Multiple criteria decision making (MCDM) theories integrate logic reasoning, mathematics, computer science, operation research and management to solve the problems of multi attributes decision making. Identifying the criteria relevant to the decision and determining their relative importance usually requires both expert judgment and specialized techniques. The MCDM approach involves problem identification, preference settings, evaluation of alternatives and selection of the best alternative.

The MCDM method uses many techniques like Simple Average Weight (SAW), Analytical Network Process (ANP), Analytical Hierarchy Process (AHP), Technique for Order Performance by Similarity to Ideal Solution (TOPSIS), Data Envelopment Analysis (DEA), Interruptive Structural Modeling (ISM), Hybrid approaches and VIKOR (ViseKriterijumskaOptimizacija I KompromisnoResenje in Serbian, meaning Multi-criteria Optimization and Compromise Solution). Peltola et al. [17] used two decision support systems Graphic State Select (GSS) and AHP for improving the performance of buyer-supplier relationship. Yang et al. [18] applied an integrated fuzzy MCDM technique for solving vendor selection problem. Banar et al. [19] used ANP to choose best alternative for land filling. Gencer and Gurpinar [20] proposed ANP for selecting suppliers in an electronic industry.

Shih et al. [21] proposed the TOPSIS technique to a group decision environment. Lin et al. [22] presented a fuzzy agility index (FAI) based on agility providers using fuzzy logic. Deng et al. [23] presented a modified TOPSIS method to evaluate and rank the relative performance of competing companies in China. Desheng et al. [24] proposed three techniques to evaluate the risks in the supply chain such as chance constrained programming (CCP), data envelopment analysis (DEA), and multi objective programming (MOP). Many researchers have studied some other MCDM methods such as PROMOTHEE, ELECTRE and Fuzzy ranking 
methods for multi criteria decision making problems [25, 26]. With this background, this study proposes a novel approach based on MCDM to identify the supplier selection factors and also to select the best supply chain partner for the leading firm engaged in manufacturing automotive products.

\section{IV.RESEARCH OBJECTIVE}

The main objective of this study is to establish the most important criteria affecting the selection of supply chain partners and to evaluate and select the potential suppliers to meet firm's needs consistently in the procurement of materials and components.

\section{RESEARCH METHODOLOGY}

In this study, the supplier selection criteria are identified through literature review and brainstorming with top management steering team of company. The outcome this exercise results that eight criteria have been identified under a set of six attributes as shown in the Table I. Then the MCDM method VIKOR is employed to achieve the final ranking of supply chain partners. Figure 1 indicates the steps involved in the proposed methodology. And the proposed method is demonstrated through a case study involving the materials procurement department of automotive products manufacturing firm.

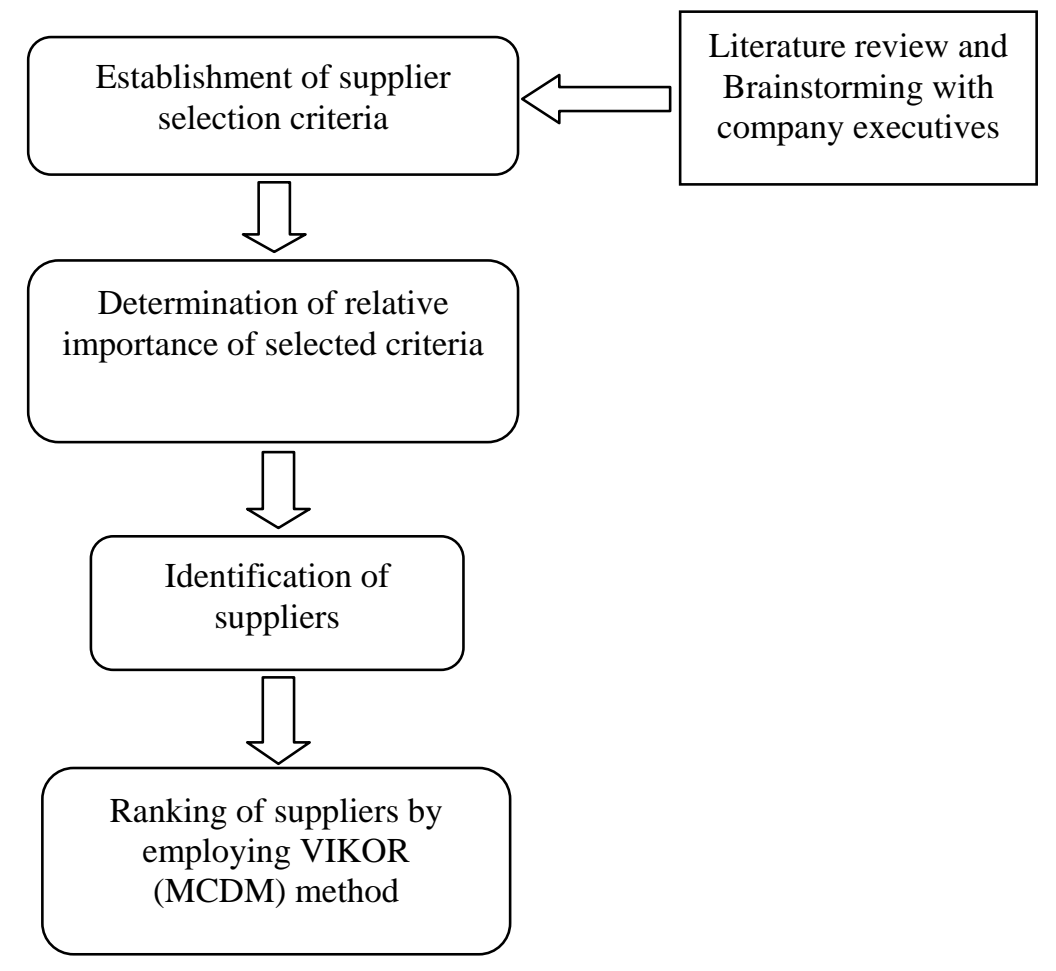

Fig.1. Proposed Methodology

\section{DESCRIPTION OF VIKOR}

VIKOR method was developed by Opricovic and Tzeng [27], Faculty of Civil Engineering, Belgrade University, SERBIA. Of the various tools, the VIKOR method is used because of the following characteristics:

- Best alternative is nearest to the positive ideal solution and farthest from the negative-ideal solution.

- Best alternative has the maximum group utility for decision makers and ensures the least regret.

- This method considers weightage in criteria and the maximum group utility (v) in decision making.

VIKOR method determines the compromise ranking solution and focuses on ranking and selecting from a set of alternatives in the presence of conflicting attributes. It introduces the multiple attribute ranking indexes based on the particular measure of nearness to the ideal solution. When compared with TOPSIS and SAW, the most important difference is the usage of the utility weight ' $\mathrm{v}$ ', and the value of ' $\mathrm{v}$ ' can be adjusted according the attitude of decision-makers. In general, the value of ' $\mathrm{v}$ ' is given 0.5 as a compromise value and the same may be larger or less than 0.5 , depends upon the attitude of majority.

Tong et al. [28] pointed out that "VIKOR is applied to derive an integrated quality measurement of several conflicting and compromising responses. Lin et al. [29] applied VIKOR method to make the decision on ERP system supplier selection. 


\section{A. Steps of VIKOR [27]}

Step 1.Formulation of DecisionMatrix: The decision matrix is formulated by a team of evaluators comprising the executives of the company. The experts in the decision making team will rate every alternative's attribute on a scale of 1-5. The average of the entire expert's rating is used to form the decision matrix.

Step 2.Normalization of DecisionMatrix: Assuming that there are $m$ alternatives, and $n$ attributes, the various ialternatives are denoted as $x_{\mathrm{i}}$. For alternative $\mathrm{x}_{\mathrm{j}}$, the rating of the $j$ th aspect is denoted as $x_{\mathrm{i}}$, i.e. $x_{\mathrm{ij}}$ is the value of the $j$ thattribute. The normalized value is calculated using the equation (1)

$$
f_{i j}=\frac{x_{i j}}{\sum_{i=1}^{n} x_{i j}^{2}}, i=1,2, \ldots m \& j=1,2, \ldots n
$$

Step 3.Determine the Weights of the Attributes: The weights of the attributes must be calculated to express their relative importance.

Step 4.Determine the Best and Worst Values:For all the attribute functions the best value was $f_{j}^{*}$ and the worst value was $f_{j}^{-}$, that is, for attribute $\mathrm{j}=1$-n, we get equations:

$$
\begin{aligned}
& f_{j}^{*}=\max f_{i j}, i=1,2, \ldots . m \\
& f_{j}^{-}=\min f_{i j}, i=1,2, \ldots . m
\end{aligned}
$$

where $f_{j}^{*}$ is the positive ideal solution (PIS) for jth criteria and $f_{j}^{-}$is the negative ideal solution (NIS) for jth criteria.

Step 5.Compute Distance of Alternatives to the Ideal Solution:This step is to calculate the distance from each alternative to the positive ideal solution and the negative ideal solution using the equations(4) and (5).

$$
\begin{gathered}
S_{i}=\sum_{j=1}^{n} w_{j} \frac{\left(f_{j}^{*}-f_{i j}\right)}{\left(f_{j}^{*}-f_{j}^{-}\right)}-(4) \\
R_{i}=\max _{j}\left[w_{j} \frac{\left(f_{j}^{*}-f_{i j}\right)}{\left(f_{j}^{*}-f_{j}^{-}\right)}\right]-(5)
\end{gathered}
$$

Step 6. Calculate the VIKOR values:The VIKOR values $\mathrm{Q}_{\mathrm{i}}$ for $i=1,2, \ldots, m$, are calculated using the equation(6)

$$
Q_{i}=\frac{v\left(S_{i}-S^{*}\right)}{\left(S^{-}-S^{*}\right)}+(1-v) \frac{\left(R_{i}-R^{*}\right)}{\left(R^{-}-R^{*}\right)}-(6)
$$

Where $\mathrm{S}^{-}=\max \mathrm{S}_{\mathrm{i}}, \mathrm{S}^{*}=\min \mathrm{S}_{\mathrm{i}}, \mathrm{R}^{*}=\min \mathrm{R}_{\mathrm{i}}, \mathrm{R}^{-}=\max \mathrm{R}_{\mathrm{i}}$ and $v$ is the "weight of the strategy of the majority of criteria" (or "the maximum group utility") reflecting the attitude of the decision makers.

Step 7.Rank the alternatives by $Q_{i}$ values: According to the $Q_{\mathrm{i}}$ values calculated by step (4), we can rank the alternatives and thereby make the decision.

\section{VII.CASE ANALYSIS}

In this study, the case company under consideration is one of the leading automotive glass products manufacturing company located in South India, offering various types of automotive products and services. A case study on selection of supply chain partners in an automotive industry is conducted to validate and illustrate the feasibility of the proposed VIKOR method. The case company purchases large number of raw materials and components from the outside. Whenever the quantity of these items falls below a significant level, the procurement department places an order to any one of the suppliers from the database. This process happens in an unorganized manner and thereby the company faces problems in maintaining quality, delivery, reliability, new product development, etc. The company has a list of seven suppliers say A1, A2, A3, A4, A5, A6 and A7 for the supply of these items. Of these suppliers, the company places the order to the supplier say for example A3 randomly without taking into account its ability regarding quality, delivery time, performance history, technical capability, etc. On delivering these items, the rejection levels were found to be $66.67 \%$ and the responsiveness to new product development was also found to be low thereby denoting poor quality and poor 
technical competence. Thus the company faces problem in selecting the right vendor for each component of their product.Hence, the company needs to implement more accurate and effective method for selecting the right supplier in order to maintain the quality and thereby enhancing the customer satisfaction. In this study, the supplier selection criteria are identified through literature review and brainstorming with top management steering team of company (decision makers) which are presented in the Table I.

TABLE I. SET OF ATTRIBUTES AND CRITERIA

\begin{tabular}{llc}
\hline \multicolumn{1}{c}{ Dimensions } & \multicolumn{1}{c}{ Criterion } & $\begin{array}{c}\text { Weight } \\
\mathbf{\%}\end{array}$ \\
\hline \multirow{2}{*}{ Quality } & C1. Durability & 30 \\
\multirow{2}{*}{ Cost } & C2. Rejection levels & 15 \\
\multirow{2}{*}{ Delivery } & C3.Value Cost Reduction & 10 \\
& C4.Geographical Location & 7 \\
\multirow{2}{*}{ Service } & C5.Lead Time & 7 \\
Management & C6. Readiness to accept and replace the rejections & 15 \\
\hline
\end{tabular}

There are 7 alternatives and 8 attributes for the materials of glass products. (Ai represent ith alternative, $i=$ $1,2, \ldots, 7, \mathrm{Cj}$ represents the jth attribute, $\mathrm{j}=1,2, \ldots, 8)$. Let the alternatives be the suppliers A1, A2, A3, A4, A5, A6 and A7 and the criteria be C1: Durability; C2: Rejection levels; C3: Value Cost Reduction; C4: Geographical Location; C5: Lead Time; C6: Readiness to accept and replace the rejections; C7: Cooperation in case of emergencies and C8: Supplier evaluation audit score. The team of evaluators (decision makers) comprising the managers of various departments such as purchase, quality control, product engineering and production engineering of case company determined the weights of the attributes based on the respective criteria to express their relative importance which is depicted in the Table I. Each and every alternative's jth attributes are evaluated with 1-5 points by evaluators; One can get the average mark of ith alternative's jth attribute and thus the decision matrix formulated by the expert team is given in the Table II.

TABLE III. DECISION MATRIX

\begin{tabular}{|c|c|c|c|c|c|c|c|c|}
\hline & C1 & C2 & C3 & C4 & C5 & C6 & C7 & C8 \\
\hline A1 & 2.59 & 1.85 & 0.12 & 2.63 & 0.83 & 2.0 & 2.0 & 3.0 \\
\hline A & 4.52 & 0.52 & 0.29 & 0.51 & 0.56 & 3.5 & 3.0 & 2.0 \\
\hline A3 & 5.0 & 0 & 0.50 & 2.50 & 0.79 & 1.0 & 4.0 & 1.0 \\
\hline A4 & 2.22 & 2.78 & 1.0 & 0.52 & 0.49 & 2.0 & 2.0 & 3.0 \\
\hline A5 & 2.14 & 3.33 & 0.23 & 0.55 & 0.52 & 3.5 & 3.0 & 2.0 \\
\hline $\mathbf{A}$ & 2.59 & 1.82 & 0.25 & 1.93 & 0.53 & 3.5 & 3.0 & 2.0 \\
\hline A7 & 3.23 & 1.59 & 0.29 & 1.24 & 0.55 & 3.5 & 3.0 & 2.0 \\
\hline
\end{tabular}

Table III shows the resultant normalized matrix, according to formula (1).

TABLE III. NORMALISED MATRIX

\begin{tabular}{|cccccccc|}
\hline 0.29 & 0.35 & 0.09 & 0.60 & 0.50 & 0.26 & 0.26 & 0.51 \\
0.51 & 0.10 & 0.23 & 0.12 & 0.34 & 0.46 & 0.39 & 0.34 \\
0.56 & 0 & 0.40 & 0.57 & 0.48 & 0.13 & 0.52 & 0.17 \\
0.25 & 0.52 & 0.81 & 0.12 & 0.30 & 0.26 & 0.26 & 0.51 \\
0.24 & 0.63 & 0.19 & 0.13 & 0.32 & 0.46 & 0.39 & 0.34 \\
0.29 & 0.34 & 0.20 & 0.44 & 0.32 & 0.46 & 0.39 & 0.34 \\
0.36 & 0.30 & 0.23 & 0.28 & 0.33 & 0.46 & 0.39 & 0.34 \\
\hline
\end{tabular}

According to the equations(2) and (3), the results are shown in the Table IV. 


\begin{tabular}{c|cccccccc}
\multicolumn{10}{c}{ TABLE IV. BEST AND WORST VALUES } \\
\hline $\mathbf{~ w}$ & $\mathbf{C 1}$ & $\mathbf{C 2}$ & $\mathbf{C 3}$ & $\mathbf{C 4}$ & $\mathbf{C 5}$ & $\mathbf{C 6}$ & $\mathbf{C 7}$ & $\mathbf{C 8}$ \\
\hline $\mathbf{A 1}$ & .30 & .15 & .05 & .02 & .03 & .15 & .05 & .05 \\
\hline $\mathbf{A 2}$ & .51 & .35 & .09 & .60 & .50 & .24 & .26 & .51 \\
$\mathbf{A 3}$ & .56 & .01 & .40 & .12 & .40 & .42 & .39 & .34 \\
$\mathbf{A 4}$ & .25 & .52 & .81 & .12 & .30 & .12 & .52 & .17 \\
$\mathbf{A 5}$ & .24 & .63 & .19 & .13 & .32 & .42 & .39 & .34 \\
$\mathbf{A 6}$ & .29 & .34 & .20 & .44 & .32 & .42 & .39 & .34 \\
$\mathbf{A 7}$ & .34 & .30 & .23 & .28 & .33 & .42 & .39 & .54 \\
\hline $\mathbf{f}$ & .56 & .63 & .81 & .60 & .50 & .42 & .52 & .51 \\
$\mathbf{f}$ & 24 & .01 & .09 & .12 & .30 & .12 & .26 & .17
\end{tabular}

Table $\mathrm{V}$ shows the results, according to the equations (4) and (5).

TABLE V. DISTANCES OF $\mathrm{S}_{\mathrm{I}} \mathrm{ANDR}_{\mathrm{I}}$

\begin{tabular}{|c|c|c|c|}
\hline Alternative & Distance of PIS $\left(\mathrm{S}_{\mathrm{i}}\right)$ & \multicolumn{2}{|c|}{ Distance of NIS (F } \\
\hline A1 & 0.51 & & 0.253 \\
\hline A2 & 0.30 & & 0.126 \\
\hline A3 & 0.38 & & 0.15 \\
\hline A4 & 0.50 & & 0.29 \\
\hline A5 & 0.44 & & 0.30 \\
\hline A6 & 0.45 & & 0.253 \\
\hline A7 & 0.40 & & 0.187 \\
\hline \multicolumn{4}{|c|}{ TABLE VI. VIKOR VALUES } \\
\hline Alternativ & V-value & $\mathbf{Q}_{\mathbf{i}}$ & Ranking \\
\hline A1 & 0.5 & 0.86 & 2 \\
\hline A2 & 0.4 & 0 & 7 \\
\hline A3 & 0.8 & 0.332 & 6 \\
\hline A4 & 0.4 & 0.946 & 1 \\
\hline A5 & 0.5 & 0.833 & 3 \\
\hline A6 & 0.3 & 0.725 & 4 \\
\hline A7 & 0.3 & 0.338 & 5 \\
\hline
\end{tabular}

Note: In general $\mathrm{v}_{\mathrm{i}}=0.5$

And the VIKOR values are calculated using the equation (6) and are presented in the Table 6. From the Table $\mathrm{VI}$, it is clear that Q4 $>\mathrm{Q} 1>\mathrm{Q} 5>\mathrm{Q} 6>\mathrm{Q} 7>\mathrm{Q} 3>\mathrm{Q} 2$ and hence the ranking is shown in the Table 7. As can be seen in Table VII, alternative A4 is ranked first and alternatives A1, A5, A6, A7, A3 and A2 are ranked second, third, fourth, fifth, sixth and seventh respectively. Thus it is clear that alternative 4 is the best supplier and alternative 2 is the worst selection. 
TABLE VII. RANKING OF ALTERNATIVES

\begin{tabular}{cc}
\hline Alternatives & Rank \\
\hline A4 & 1 \\
A1 & 2 \\
A5 & 3 \\
A6 & 4 \\
A7 & 5 \\
A3 & 6 \\
A2 & 7 \\
\hline
\end{tabular}

Hence, it is found that the VIKOR method is very appropriate for supply chain partners' selection. By this method, the case company acquired the best partners and also can exemplify the approach of decision-makers by adjusting the value of utility weight ' $\mathrm{v}$ '. The VIKOR method realizes the combination of quantitative and qualitative analysis, which makes it, be a better MCDM method than others.

\section{SOFTWARE DEVELOPMET}

The above evaluation is very specific and has been done only for case organization. In order to make the ranking generic, simple software has been developed by using ' $\mathrm{C}$ ' language. When any changes in performance of suppliers on selection criteria, the entire process for ranking of suppliers is to be carried out again for finding out the best supplier. Now it is felt that a standard simulation software which could perform the above processing steps is essential for minimizing the time and cost of selection process. With this aim, the standard software TC (Turbo C) was developed in to meet the current requirement. This software package can be simulated several numbers of times with changing the values of the input parameters to get optimal solution.

\section{CONCLUSION}

Evaluation and selection of supply chain partners is a-critical business competency. Industrial firms use these results as a means to foster communications and a starting point for supplier development and performance improvement. In this study, an attempt has been made to optimize the supply chain partner by involving MCDM method VIKOR. The best supply chain partner selected by VIKOR method is found to be closer to the positive ideal solution and farthest away from the negative ideal solution and hence more accurate supplier rating can be obtained when compared to any other method. With the aim of minimizing the time and cost of supplier selection process, software was developed by using ' $\mathrm{C}$ ' language considering various factors such as quality, cost, delivery, service and management as input to select the best supplier as an output.

\section{REFERENCES}

[1] R.B. Handfield, and E.L. Nichols, Introduction to Supply Chain Management, Prentice-Hall, NJ.1999.

[2] M. Tracey and C.L.Tan, "Empirical analysis of supplier selection and involvement, customer satisfaction, and firm performance”,Supply Chain Management: An International Journal, vol. 6 (4), pp.174-188,2001.

[3] De Boer, E.Labro and P.Morlacchi, “A review of methods supporting supplier selection”, EuropeanJournal of Purchasing and Supply Management, vol. 7(2), pp.75-89.2001.

[4] A.Cox "Power, Value and SCM", Supply Chain Management: An International Journal, vol.4(4), pp.167-175.1999.

[5] L.H. Harps, “The Haves and the Have Nots: Supply Chain Practices for the New Millenium”, Inbound Logistics Journal, pp.75114.2000.

[6] R.Vera, and M.E.Pullman, “An analysis of the supplier selection process”, Omega: International Journal of Management Science, vol. 26(6), pp.739-750.1998.

[7] E.G.Stanley, and M.M. Gregory, 2001, Achieving World Class Supply Chain Alignment: Benefits, Barriers and Bridges, A CompiledResearch Report. 2001.

[8] B.Beamon, "Measuring supply chain performance”, International Journal of Operations and Production Management, vol.19 (3), pp.275-292.1999.

[9] K.S.Bhutta, and F.Huq, "Supplier selection problem: a comparison of total cost of ownership and analytical hierarchy process approach”, Supply Chain Management: An International Journal, vol.7, pp.126-135.2002.

[10] A.Petroni, and M.Braglia, "Vendor selection using principal component analysis”, Journal of Supply Chain Management, vol. 36(2), pp.63-69. 2000.

[11] R.C. Lamming, T. Johnsen, J.Zheng, and C.Harland, “An initial classification of supply networks”, International Journal ofOperations and Production Management, vol. 20(6), pp.675-691.2000.

[12] M.Kotabe, and J.Y.Murray, “Outsourcing Service Activities”, Journal of Marketing Management, vol.10(1), pp.40-45. 2001.

[13] K.Shahadat, "Supplier choice criteria of executing agencies in developing countries", International Journal of Operations andProduction Management, vol. 16(4), pp.261-285.2003.

[14] V.R. Kannan, and K.C.Tan, "Attitudes of US and European managers to supplier selection and assessment and implications for business performance”, Benchmarking: An International Journal, vol.10(5), pp.472-489.2003.

[15] M. Bevilacqua, and A.Petroni, "From traditional purchasing to Supplier Management: A Fuzzy Logic- based approach tosupplierselection”, International Journal of Logistics Research and Applications, vol. 5(3), pp.235-255. 2002.

[16] C.Kahraman, U. Cebeci, and Z.Ulukan, "Multi-criteria supplier selection using fuzzy AHP”, Logistics Information Management, vol. 16(6), pp.382-394.2003. 
[17] S. Peltola, M. Torkkeli, and J.Tuimala, "Integrating GSS and AHP: experiences from benchmarking of buyer-supplier relationships,Proc. 35th Hawaii International Conference on System Sciences, IEEE Computer Society, pp. 38. 2002.

[18] J.L.Yang, H.N.Chiu, G.H. Tzeng, and R.H. Yeh, "Vendor selection by integrated fuzzy MCDM techniques with independent and interdependent relationships”, Information Sciences, vol. 178(21), pp.4166-4183. 2008.

[19] M. Banar, B.M.Köse, A. Özkan, and I.P.Acar, “Choosing a municipal landfill site by analytic network process”, Environmental Geology, vol. 52(4), pp.747-751. 2007.

[20] C.Gencer, and G.Gurpinar, "Analytic network process in supplier selection: A case study in an electronic firm", AppliedMathematicalModeling, vol. 31(11), pp.2475- 2486. 2007.

[21] H.S.Shih, H.J. Shyur, and E.S.Lee, “An extension of TOPSIS for group decision making”, Mathematical and Computer Modeling,vol. 45(7-8), pp.801-813. 2007.

[22] C.T.Lin, H.Chiu, and P.Y.Chu, 2006, “Agility index in the supply chain”, International Journal of Production Economics, vol. 100(2), pp.285-299.2006.

[23] H. Deng, C.H.Yeh, and R.J. Willis, "Inter-company comparison using modified TOPSIS with objective weights", Computers \& Operations Research, vol.27 (10), pp.963-973.2000.

[24] Wu. Desheng, and L.O. David, “Supply chain risk, simulation, and vendor selection”, International Journal of Production Economics, vol. 114(2), pp.646-655.2008.

[25] E. Triantaphyllou, Multi-Criteria Decision Making Methods: A Comparative Study, Dordrecht: Kluwer Academic Publishers.2000.

[26] S.Opricovic, and G.H.Tzeng, “Compromise solution by MCDM methods: a comparative analysis of VIKOR and TOPSIS”,European Journal of Operational Research, vol. 178, pp.514-529.2007.

[27] S.Opricovic, and G.H.Tzeng, "Compromise solution by MADM methods: A comparative analysis of VIKOR and TOPSIS", European Journal of Operational Research, vol.156(2), pp.445-455.2004.

[28] L.I. Tong, C.C.Chen, and C.H.Wang, “Optimisation of multi-response processes using the VIKOR method”, InternationalJournalof Advanced Manufacturing Technology, vol.31, pp.1049-1057.2007.

[29] J.H.Lin, G.H. Tzeng, and W.L.Jen, "Utilizing VIKOR to make ERP system supplier selection decision”, Agriculture and Economics, vol. 34(11), pp.69-90.2005

\section{AUTHOR PROFILE}

K.G.Rajasekaran obtained his Bachelor's degree in Mechanical Engineering from Madras University, Chennai, India, Master's degree in Computer Aided Design from Anna University, Tamil Nadu, India and currently doing Ph.D in Mechanical Engineering at SathyabamaUniversity, Chennai, Tamilnadu,India. His specialization includes Supply Chain Management and Product Design and Development.

Dr. G.B.Bhaskar is an Associate Professor at the Department of Production Engineering, Anna University, MIT Campus, Chennai, Tamil Nadu, India. He received his Ph.D degree in Mechanical Engineering from Anna University, Chennai, Tamilnadu, India, Master degreein Manufacturing Engineering from IIT Madras, Tamilnadu, India, and Bachelor degree in Mechanical Engineering from Madras University, Tamil Nadu, India.His areas of interest include Supply Chain Management, Product Design and Development, Composite Materials, Manufacturing.

Dr.S.Murali is an AssociateProfessor at the Department ofMechanical Engineering, Vels University, Chennai, Tamilnadu, India. He received his Ph.Ddegree in Manufacturing Engineering, Bachelor and Master degreein Production Engineering from Annamalai University,Chidambaram, Tamil Nadu, India. He received his MBA degree from Bharathidasan University, Trichy, Tamil Nadu,India. His areas of interest include Production/ServiceOperations Management, Statistical Applications toManufacturing and Supply Chain Management, Product Design and Development and Materials Processing.

Dr.M.Chandrasekaran is Professorand Director of Department of Mechanical Engineering, Vels University, Chennai, Tamilnadu, India.He completed his Master's and Doctorate degree in Production Engineering at National Institute of Technology, Trichy, India. His areas of interest include Scheduling, Multi Objective Optimization, Supply Chain Management, Computer Integrated Manufacturing and Composites. 